\title{
IMPLANTAÇÃO DAS CINTADEIRAS AUTOMÁTICAS NA LINHA LEVE DA ARCELORMITTAL CARIACICA*
}

\author{
Gustavo dos Santos Guimarães ${ }^{1}$ \\ Edson Barcelos ${ }^{2}$ \\ José Aparecido Pereira ${ }^{3}$
}

\begin{abstract}
Resumo
$\mathrm{Na}$ Linha Leve da Laminação da Usina ArcelorMittal Cariacica o cintamento dos feixes de barras e perfis leves era feito manualmente através de cintadeiras pneumáticas envolvendo 8 operadores e representando um gargalo nos feixes mais leves de 1,0 e 1,5 t. Com a finalidade de eliminar o gargalo de produção e redução de mão de obra braçal foram implantadas 3 cintadeiras automáticas no trecho entre o empilhador de barras e o sistema de pesagem e etiquetagem.
\end{abstract}

Palavras-chave: Cintamento; Feixes; Cintadeiras.

\section{IMPLEMENTATION OF AUTOMATIC STRAPPING MACHINES IN THE LIGHT SECTION ROLLING MILL OF THE ARCELORMITTAL CARIACICA}

\section{Abstract}

At the Light Section Rolling Plant of ArcelorMittal Cariacica the strapping of the bundles of bars and light sections was done manually by pneumatic strappers involving 8 operators and representing a bottleneck in the lighter bundles of 1.0 and $1.5 \mathrm{t}$. In order to eliminate the bottleneck of production and to reduce the manual labor were implemented 3 Automatic Strapping Machines in the space between the stacker and the weighing and labeling system.

Keywords: Strapping; Bundles; Strapping machines.

1 Engenheiro Mecânico, Engenheiro de Projetos da ArcelorMittal Brasil-Longos, B. Hte, MG, Brasil. Engenheiro Mecânico, Supervisor de Engenharia da ArcelorMittal Cariacica, Cariacica, ES, Brasil. Engenheiro Mecânico, Consultor de laminação, J. A. Pereira Consultoria de Engenharia, Vila Velha, ES, Brasil. 


\section{INTRODUÇÃO}

A Linha Leve da ArcelorMittal Cariacica lamina produtos longos: Barras e Perfis Leves (MBQ - Merchant Bar Quality) com o seguinte mix de produtos:

- Cantoneira de Abas Iguais:..... 1 1/4" a 2 1/2"

- Barra Chata Estrutural: $11 / 2 "$ a $4 "$

- Barra Chata Mola: $11 / 2$ " a 4 1/2"

- Barra Redonda Mecânica:........5/8" a $17 / 8 "$

- Vergalhão: 10 a $25 \mathrm{~mm}$

- Lâmina para Tear Granito:

100 a $110 \mathrm{~mm}$

Estes produtos são empacotados no Empilhador de Barras formando feixes com comprimento de 5 a $12 \mathrm{~m}$ e com peso variando de 1,0 a 2,5t. A amarração é feita com fitas metálicas de $0,8 \times 32 \mathrm{~mm}$ e até o final de 2014 o cintamento era realizado manualmente através de cintadeiras pneumáticas, sendo que cada feixe recebe de duas a cinco cintas dependendo das suas características. Na parada de final de ano foram instaladas 3 Cintadeiras Automáticas entre o Empilhador de Barras e o Sistema de Pesagem e Etiquetagem

\section{DESENVOLVIMENTO}

\subsection{Situação Anterior}

O material laminado seguia o fluxo conforme mostrado na Figura 1.

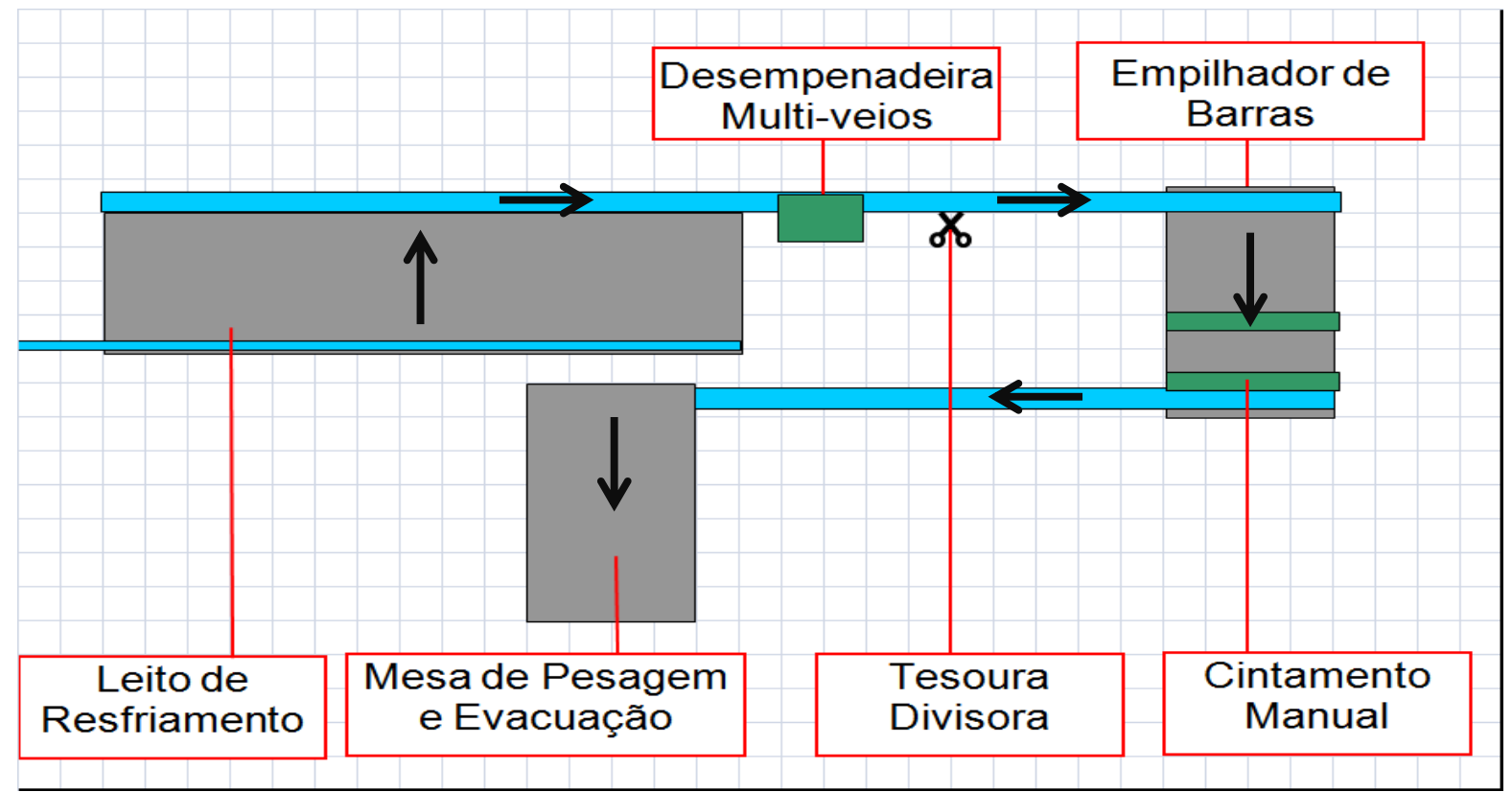

Figura 1 - Fluxograma da área de Acabamento

Após ser formatado o feixe era transportado verticalmente e parava numa posição intermediária para ser cintado manualmente através de cintadeiras pneumáticas, trabalho este executado por dois operadores em quatro turmas num total de oito, conforme mostrado na Figura 2. 


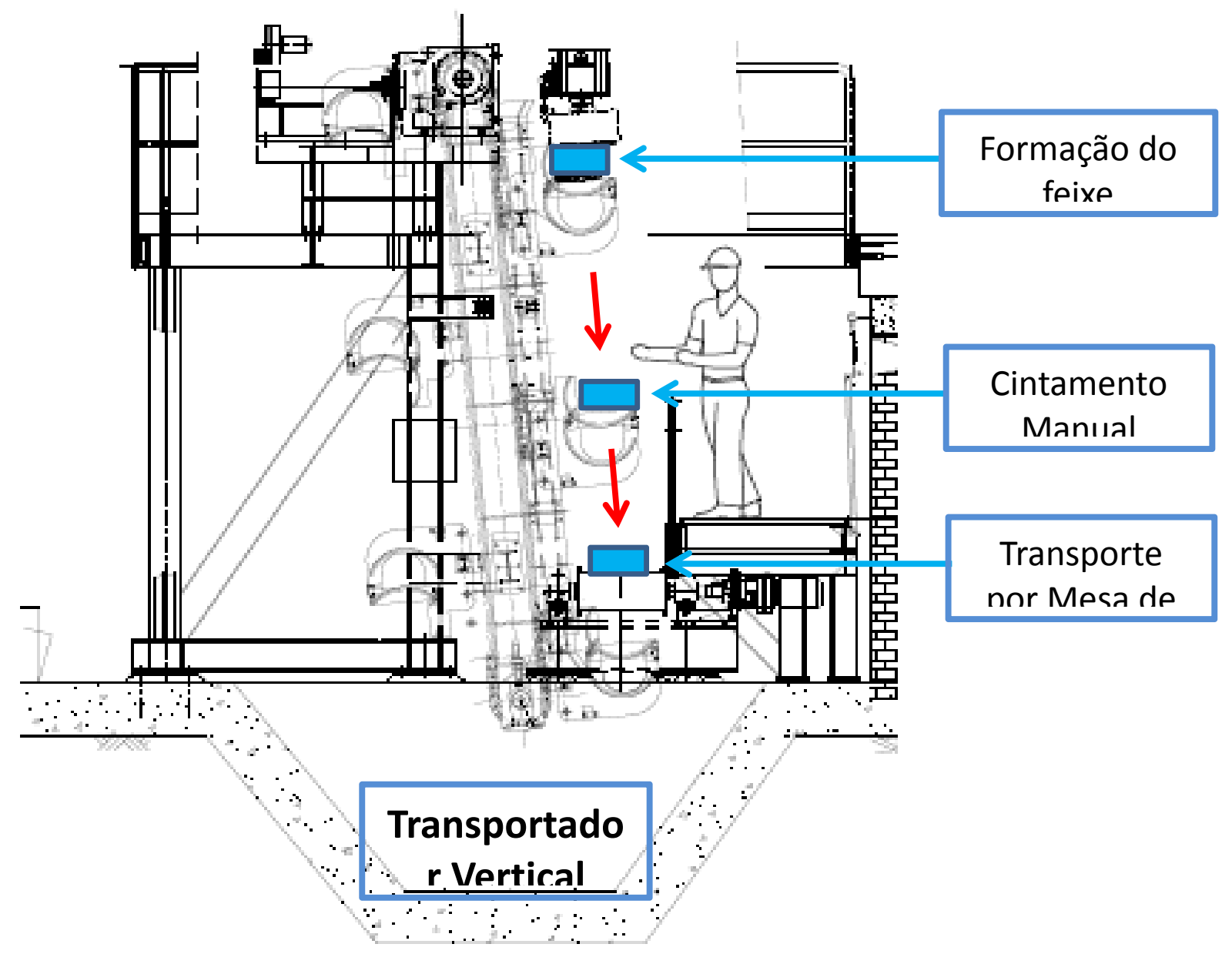

Figura 2 - Cintamento manual

Este sistema apresentava as seguintes desvantagens:

- Uso intensivo de mão de obra:...Custo fixo

- Gargalo nos feixes leves: Perda de produtividade

- Trabalho manual repetitivo: Ergometria

\subsection{Especificação}

Dentro do planejamento de investimento de 2013 para 2014/15 foram aprovados diversos projetos para redução de gargalos e redução de custo, dentre eles a instalação das Cintadeiras Automáticas.

O projeto foi definido de acordo com as seguintes premissas:

- Lay-out integrado ao Empilhador e Sistema de Pesagem (Figura 3);

- Conjunto formado por três máquinas;

- Possibilidade de se operar com três, duas ou uma máquina;

- Operação totalmente automática;

- Automação integrada à automação do Empilhador e Sistema de Pesagem;

- Automação reversível ao sistema anterior para o período de start-up;

- Máquinas com distância entre centros fixa;

- Mesa de rolos preparada para receber feixes de barra chata;

- Formatador de feixe para barra redonda e vergalhão. 


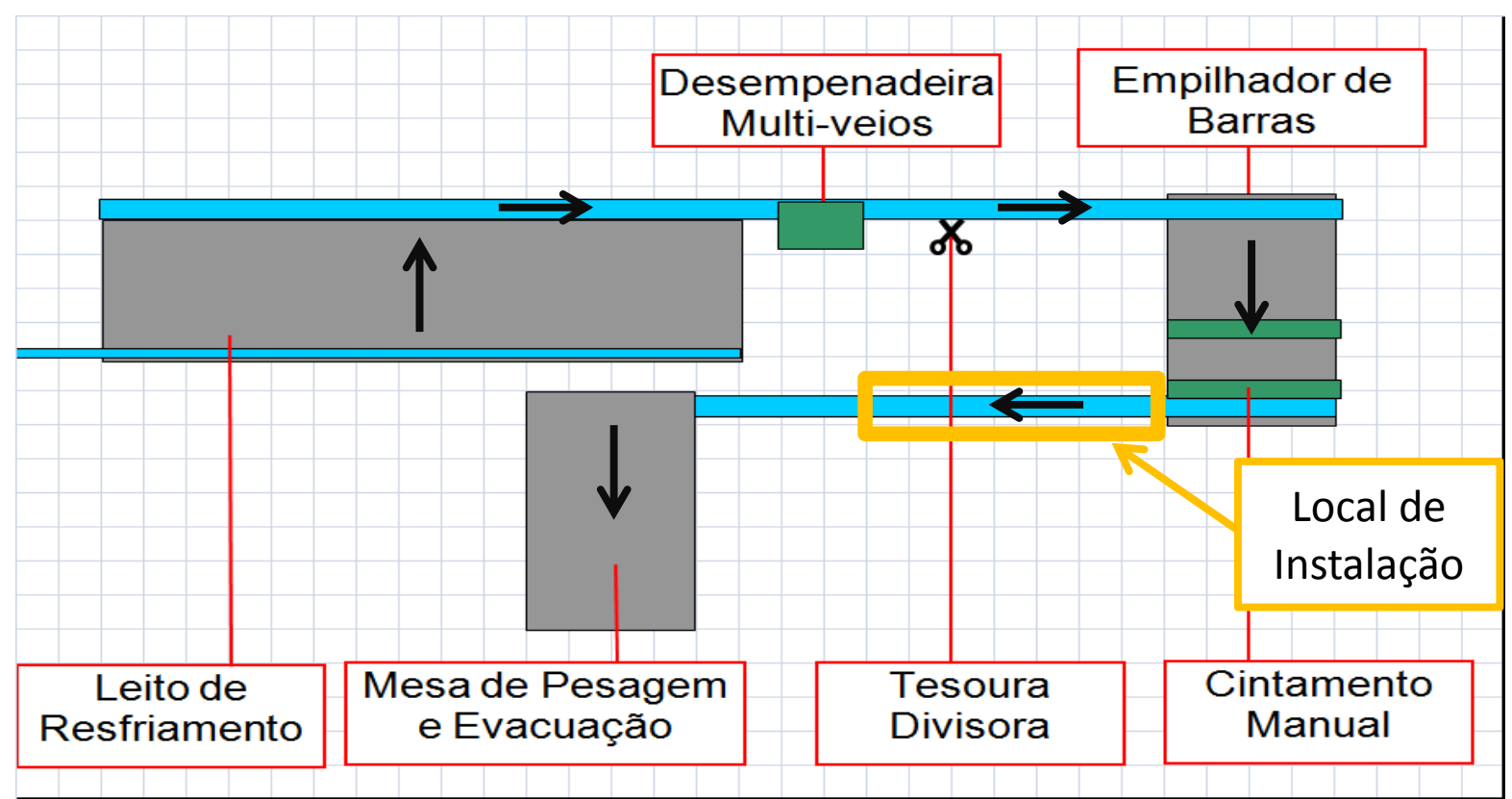

Figura 3 - Local da Instalação

Estudos anteriores já tinham definido a necessidade de se ter três máquinas para atender à produtividade de até $80 \mathrm{t} / \mathrm{h}$ com feixes de 1,0 t e cinco amarrações, apesar de se ter feixes com comprimentos especiais que demandariam espaçamentos entre cintas variáveis ( $7 \%$ da produção) se optou por máquinas com distância entre centros fixa para evitar problemas de manutenção no sistema de translação. Para se ter possibilidade de realizar manutenção preventiva durante a produção de feixes com menor quantidade de cintas, a automação deveria estar preparada para operar com duas máquinas ou até uma no caso de pane.

A automação foi especificada para operar no sistema antigo durante o período de comissionamento e start-up.

Como o transportador vertical tem uma inclinação de $5^{\circ}$, se tomou especial atenção na transição do feixe de barras chatas deste transportador para a mesa de rolos a fim de evitar a desformatação do mesmo com queda de barras.

Baseado nestas premissas foi elaborado a especificação técnica (Escopo de fornecimento) e escolhidas três empresas com atuação no ramo para apresentação das propostas técnicas.

\subsection{Análise das Propostas}

Quanto ao tipo de cravação da cinta foram analisadas três opções:

- Cravação por selo;

- Cravação sem selo por solda;

- Cravação sem selo por sobreposição.

A cravação sem selo por solda é uma tecnologia nova que a princípio funciona bem, mas requer manutenção periódica dos eletrodos. A cravação por selo é o sistema tradicional que além do de ter o custo do selo, requer um sistema de alimentação apropriado. A opção final foi pela cravação por sobreposição que não usa selo, apresenta segurança na fixação e requer baixa manutenção. (Figura 4). 

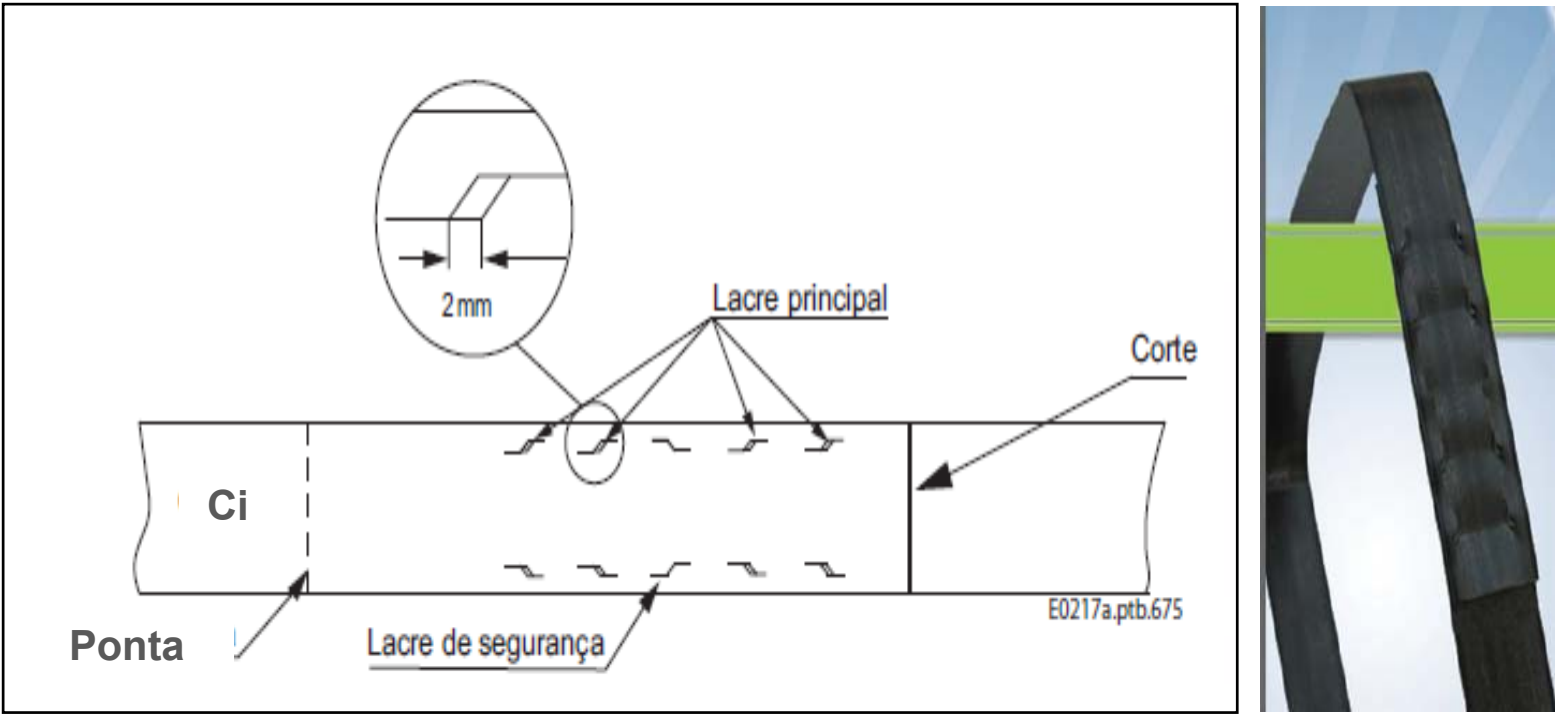

Figura 4 - Cravação por sobreposição

\subsection{Concepção do Projeto}

Duas empresas foram escolhidas para fornecimento dos equipamentos, conforme lay-out abaixo (Figura 5):

- Sund Birsta [1-2]: Mesa de rolos - Cintadeiras - Formador de feixes;

- Factory-Automação Industrial [3]: Integração da automação - Automação da mesa de rolos - Equipamentos elétricos.

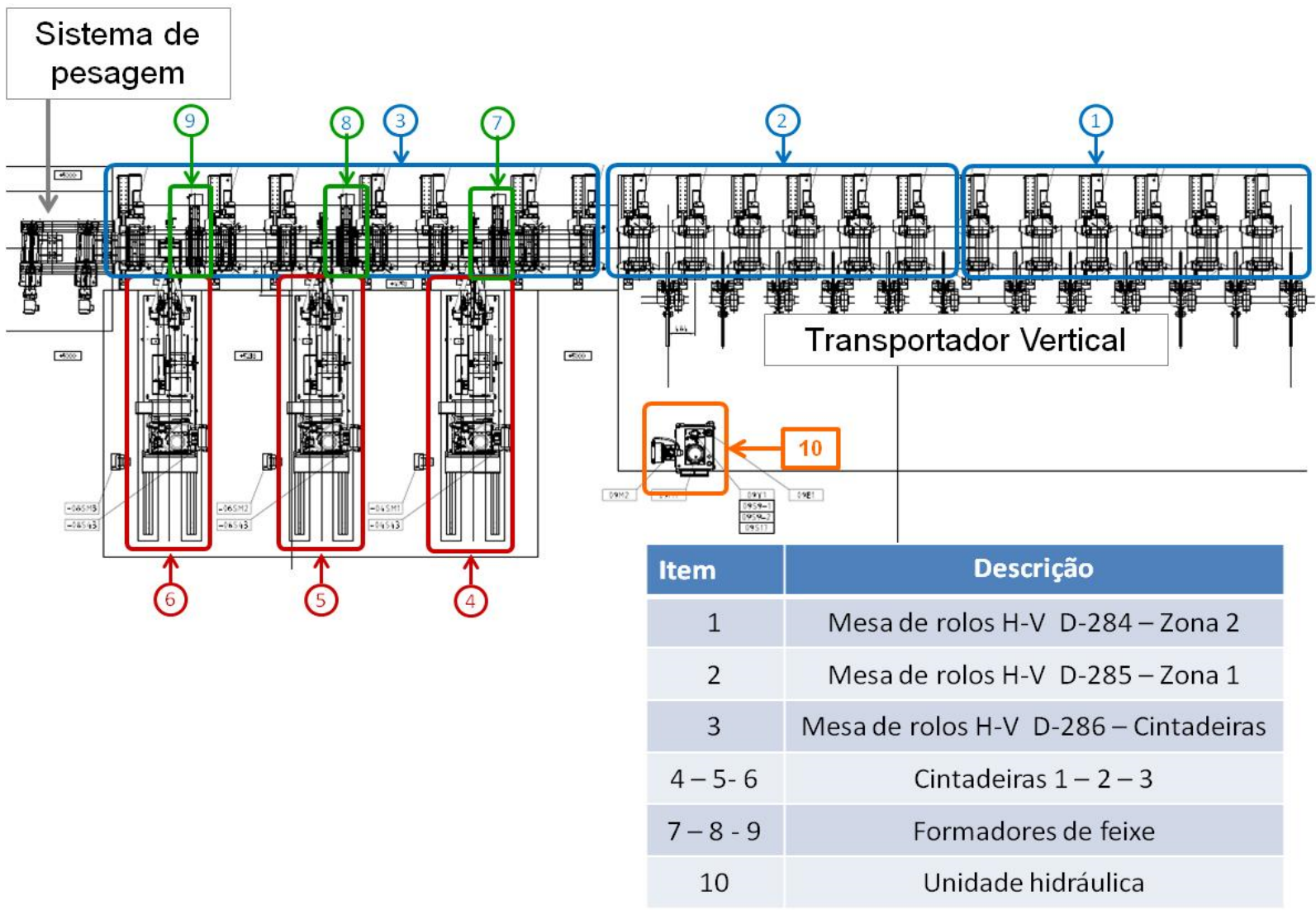

Figura 5 - Lay-out do projeto 


\subsubsection{Mesas de rolos}

Características (Figuras 6 e 7):

- Rolos horizontais com a mesma inclinação do transportador vertical - $5^{\circ}$;

- Rolos verticais com largura ajustável hidraulicamente;

- Esta largura é ajustável de acordo com a largura do feixe, com valores para recebimento transporte e cintamento;

- Montagem com aproveitamento da base civil no trecho do Transportador Vertical.

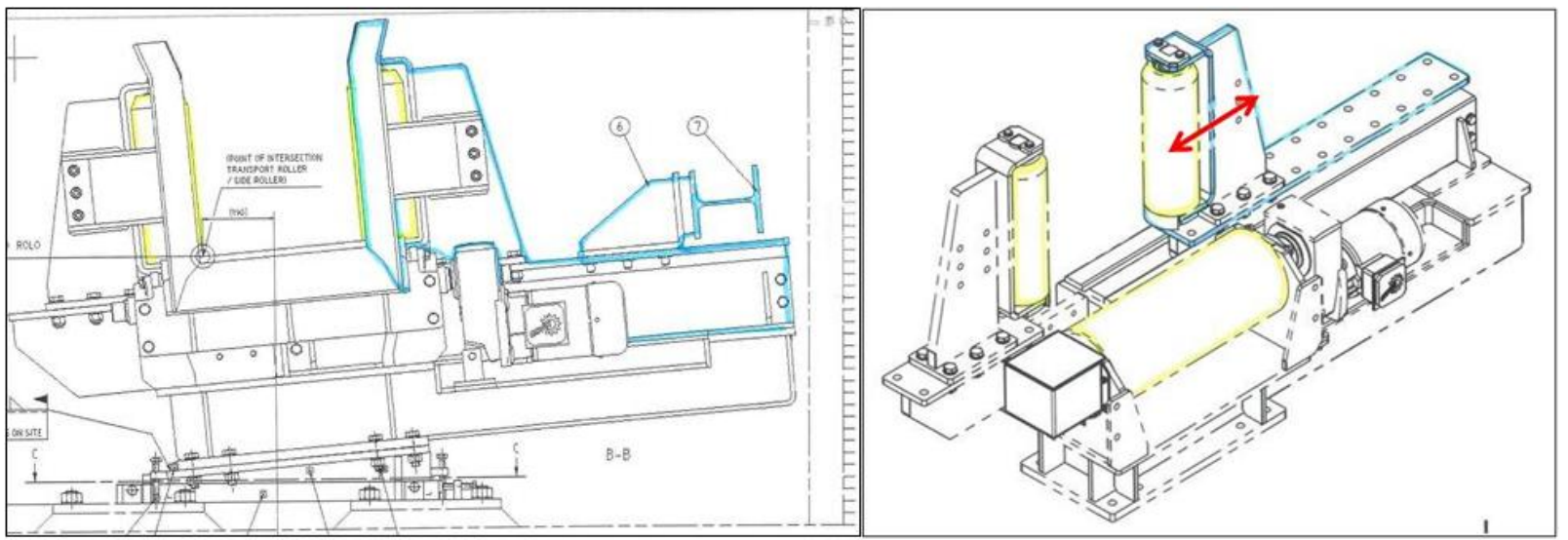

Figuras 6 e 7 - Mesa de rolos

\subsubsection{Cintadeira}

\section{Características (Figura 8):}

- Automação on board;

- Unidade hidráulica on board;

- Cravação por sobreposição;

- Desbobinador para bobina jumbo - Até 1000 kg;

- Guia da cinta fixa;

- Todos os acionamentos do cabeçote são hidráulicos;

- Retrátil para reposição de bobina e manutenção.

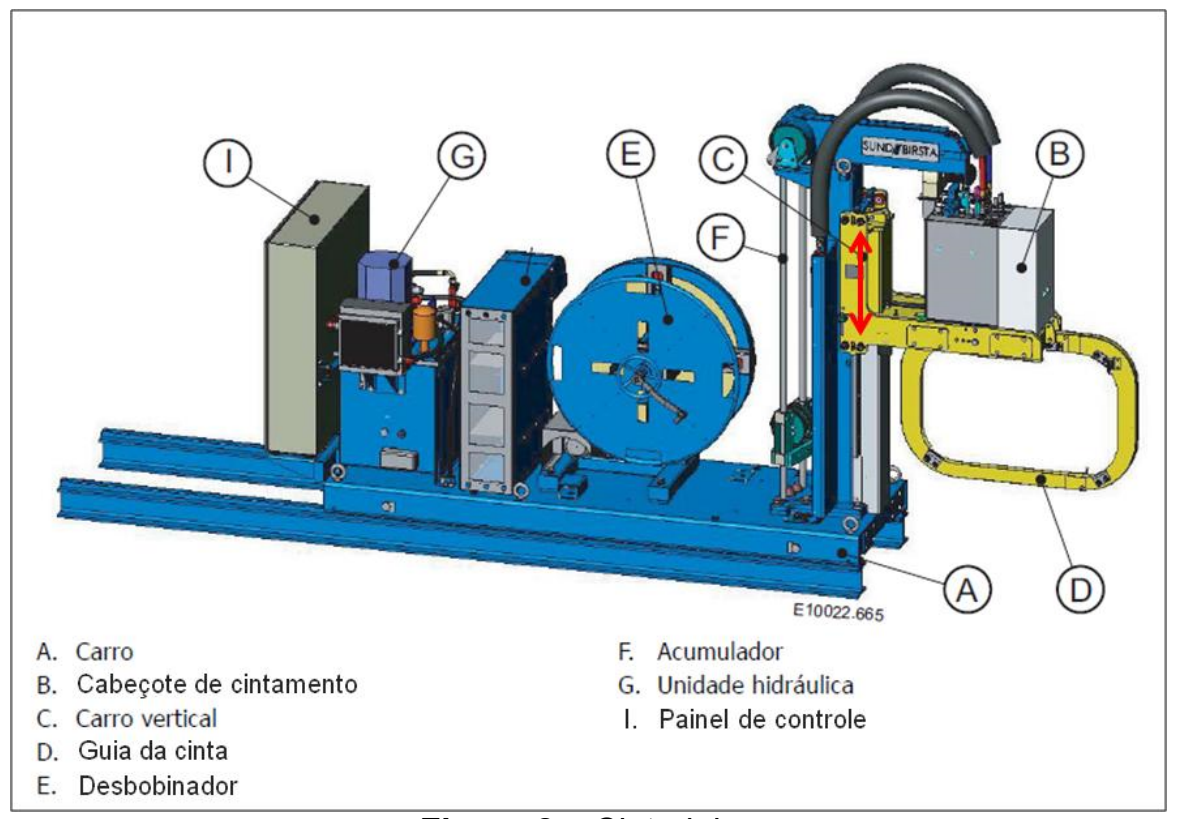

Figura 8 - Cintadeira 


\subsubsection{Formador de feixes}

Características (Figuras 9 e10):

- Acionamento por cilindro hidráulico;

- Concepção para feixes grandes ou pequenos;

- Acionamento pela unidade hidráulica da mesa de rolos.
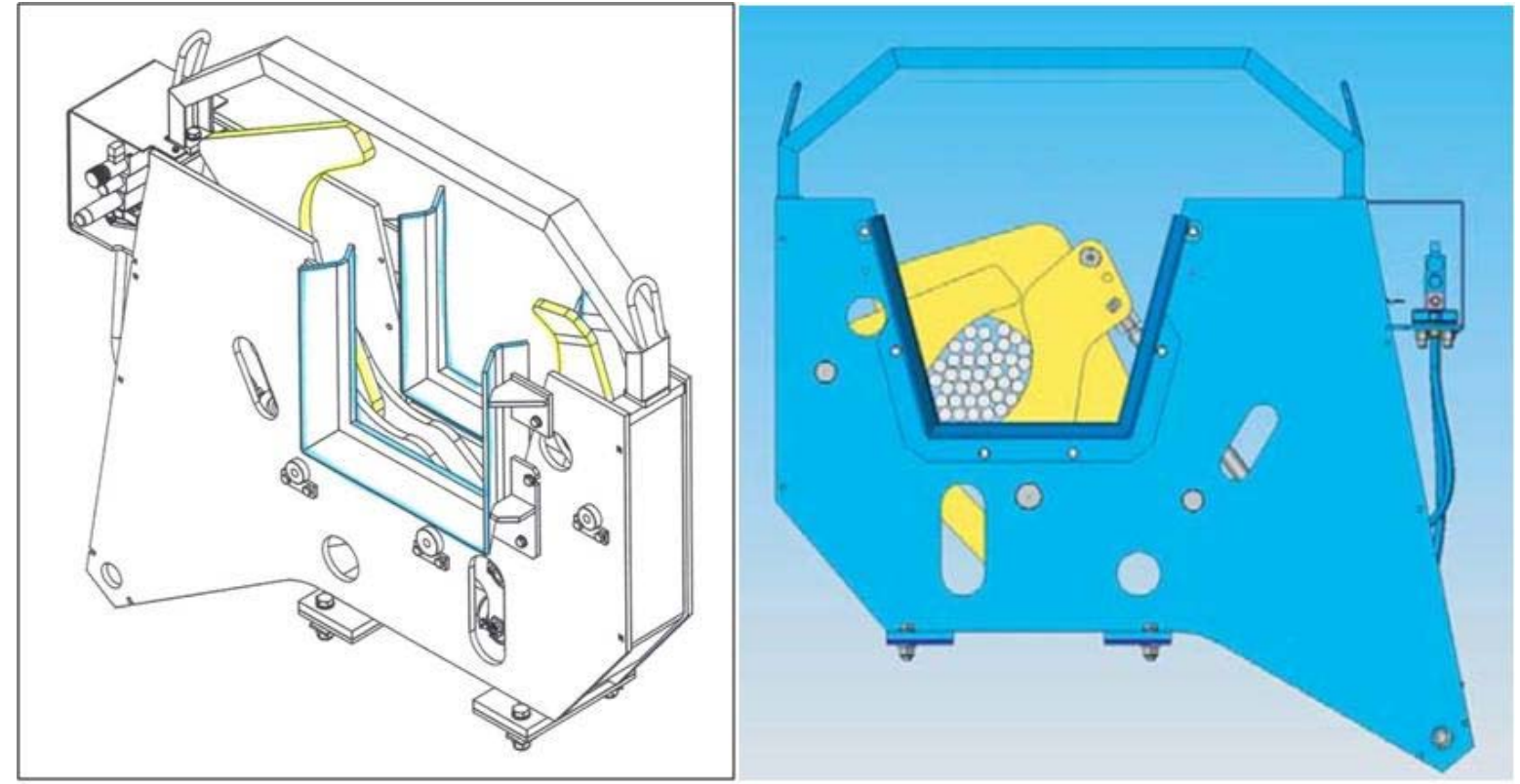

Figuras 9 e 10 - Formador de feixes

\subsection{4 - Mesa de comando}

A mesa de comando dos novos equipamentos incorporou as funções da mesa anterior do sistema de pesagem, alem de ter uma IHM que permite ajustar todos os parâmetros de funcionamento do sistema em conexão com sistema supervisório onde são armazenas as receitas para cada tipo de feixe. (Figura 11).
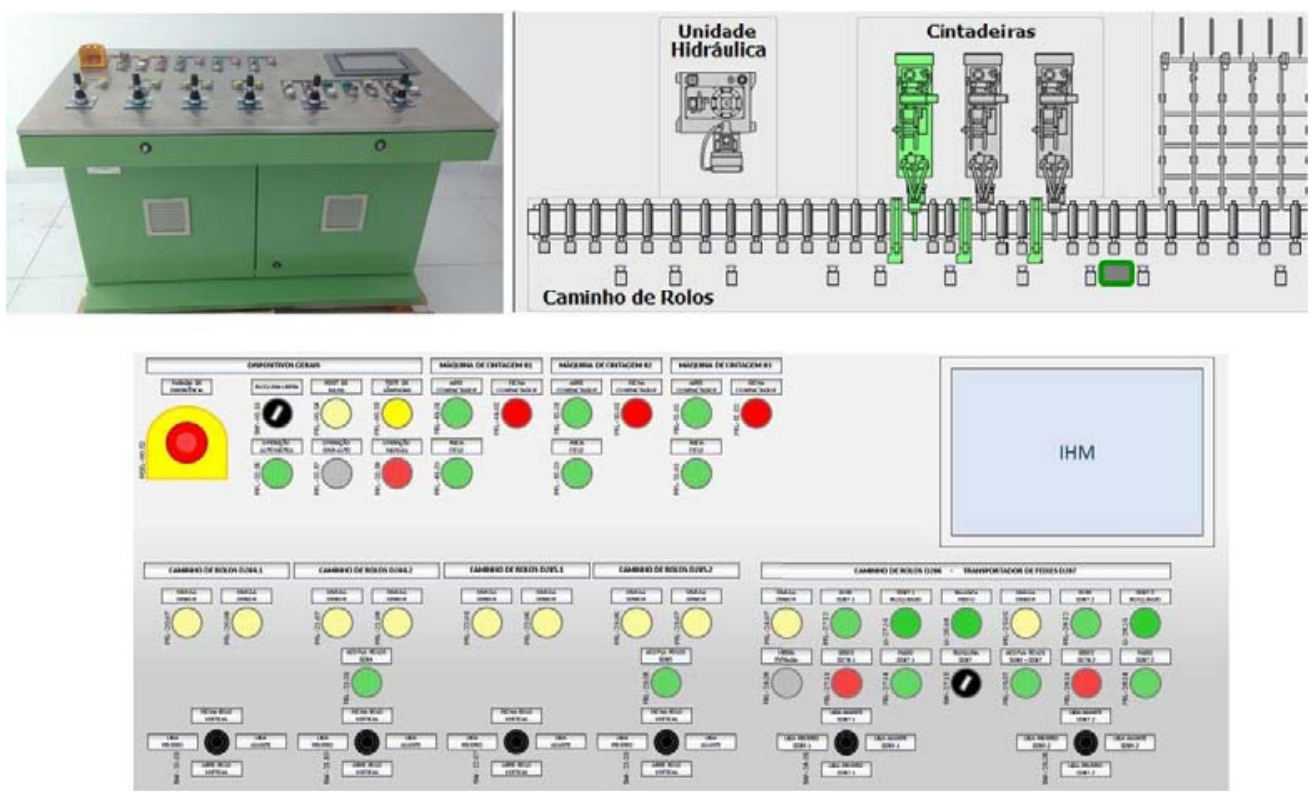

Figura 11 - Mesa de comando 


\section{MONTAGEM E START-UP}

\subsection{Preparação}

A figura 12 mostra as mesas de rolos que seriam desmontadas. Parte da obra civil foi feita com o laminador em operação (Figura 13).
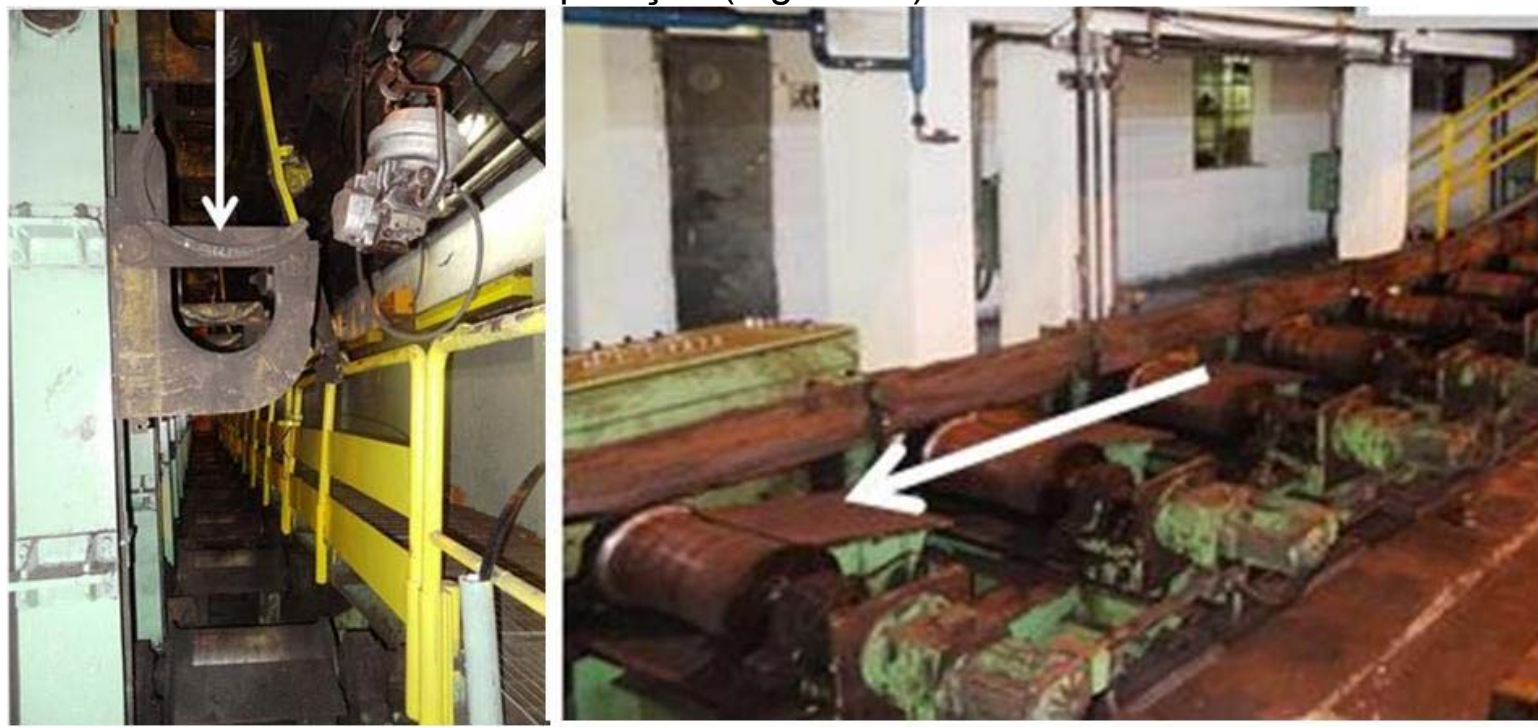

Figura 12 - Mesas de rolos que foram substituídas
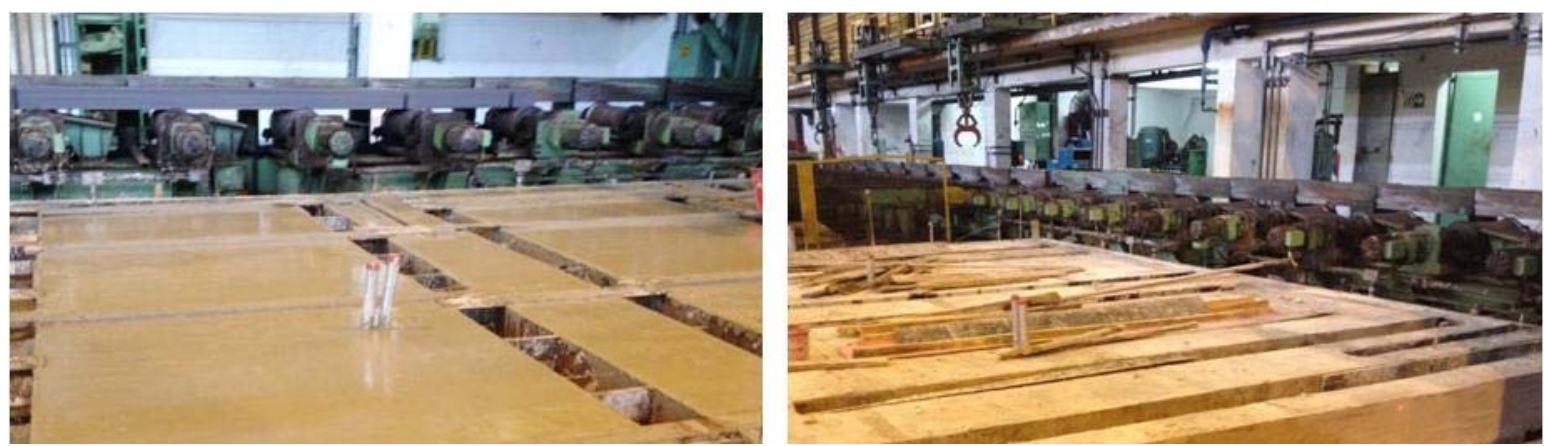

Figura 13 - Obra civil com mesa de rolos anterior ao fundo

\subsection{Desmontagem - Obra civil - Montagem}

Durante a parada de 20 dias do final de Dez/14 foi feita a desmontagem dos equipamentos, obra civil, montagem elétrica e mecânica. O planejamento foi feito de modo que as mesas de rolos voltassem a funcionar em conjunto com laminador no início de Jan/15 e com o cintamento em manual.

\subsection{Comissionamento - Start-Up}

$\mathrm{Na}$ primeira quinzena de Jan/15 foi feito o comissionamento das Cintadeiras, formadores de feixe e dos rolos verticais. O start-up, colocação em marcha, treinamento dos operadores, mecânicos e eletricistas terminou no final de Janeiro. $O$ equipamento entrou em operação definitiva a partir de Fevereiro com performance $100 \%$ em relação ao planejado (Figura 14). O cintamento e a qualidade da cravação atendeu perfeitamente às exigências dos termos do Teste de Performance.

$\mathrm{Na}$ figura 15 são mostrados exemplos de feixes cintados pelas Cintadeiras Automáticas. 

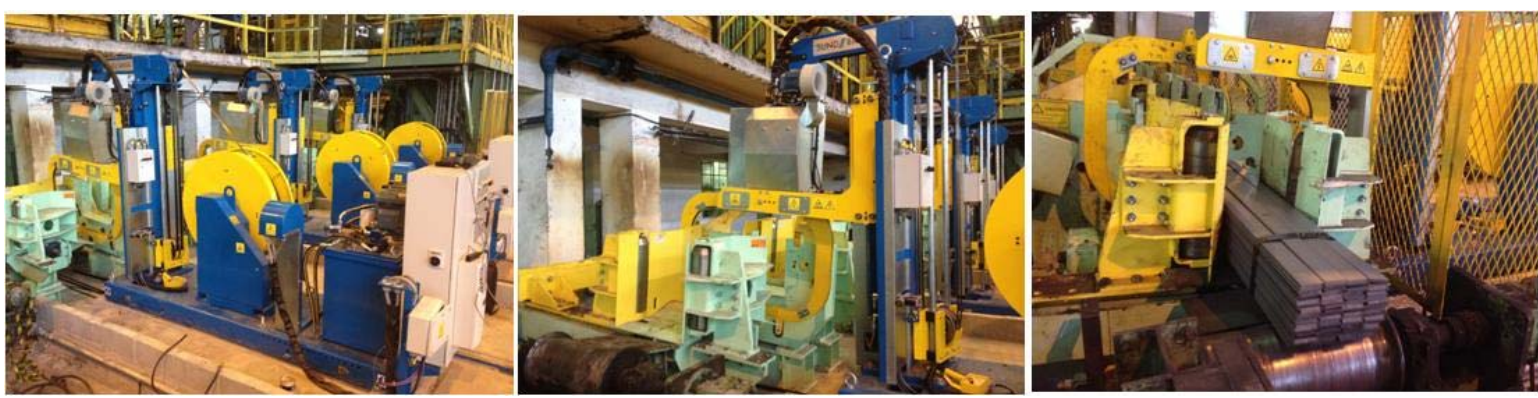

Figura 14 - Cintadeiras e mesa de rolos montadas - Feixe de barra chata em cintamento
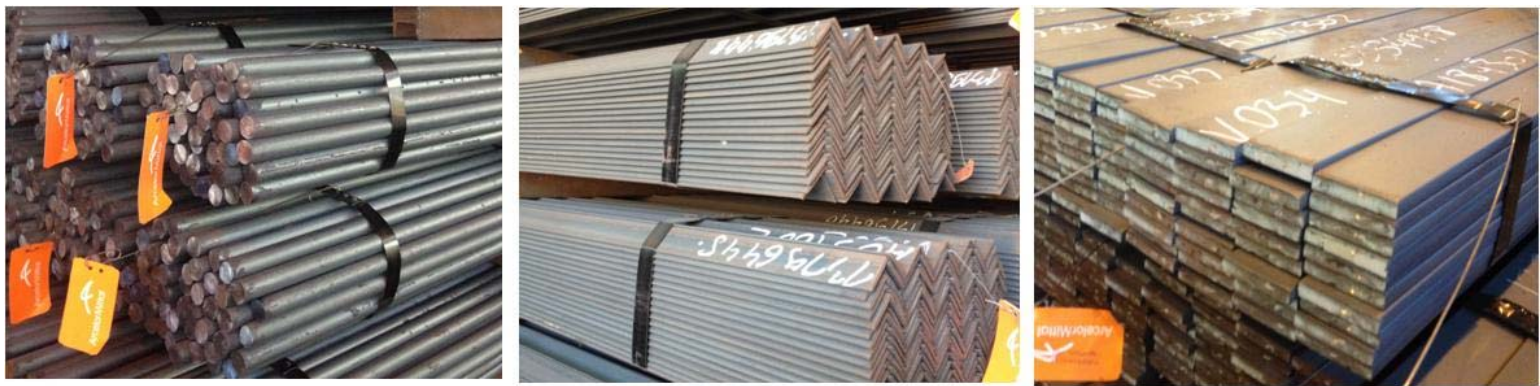

Figura 15 - Feixes cintados nas Cintadeiras Automáticas

\section{CONCLUSÃO}

As soluções adotadas e as escolhas realizadas mostraram-se acertadas e hoje a ArcelorMittal Cariacica dispõe de um equipamento totalmente automatizado, altamente confiável e com baixíssimo nível de intervenção operacional e de manutenção.

\section{REFERÊNCIAS}

SUND BIRSTA, Manual de operação e manutenção - Cintadeiras, 2014

2 SUND BIRSTA, Strapping Machines SMA , Internet, 2014

3 FACTORY-AUTOMAÇÃO INDUSTRIAL, Manual do sistema supervisório, 2014 